\title{
A Review on Intestinal and Blood parasitic (Haemoparasite) protozoans
}

Received: 22 October, 2020

Accepted: 08 December, 2020

Published: 10 December, 2020

*Corresponding author: Said Muhammed Hussen Salale University, College of Agriculture and Natural Resource, Ethiopia, E-mail: saidmuh2011@gmail.com

https://www.peertechz.com

\author{
Said Muhammed Hussen* \\ Salale University, College of Agriculture and Natural Resource, Ethiopia
}

\begin{abstract}
Parasites are a major cause of disease of man and domestic animals. More than half the human population lives in misery and pain and suffers vast economic losses due to parasites. Protozoa are ubiquitous throughout aqueous environments and the soil, and play an important role in their ecology. Optimal recovery and microscopic identification of protozoa from patients with intestinal infections is dependent on proper collection and preservation of fecal specimens. The most reliable way to diagnose a parasitic infection is by detection and identification of the infecting organism. All methods for the direct identification of parasites fail if the parasite density in the specimen is below the sensitivity of the method employed, or if the parasite cannot be directly demonstrated due to the life cycle in the host. In such cases indirect methods must be used. Ideally, serology should allow differentiation between recent and latent infections and should be able to demonstrate whether an animal is carriers as well as the elimination of the parasite after therapeutic measures have been applied.
\end{abstract}

\section{Introduction}

Parasites are a major cause of disease of man and domestic animals. More than half the human population lives in misery and pain and suffers vast economic losses due to parasites. A possible solution to these problems lies in the development of new agricultural technologies for expanding food production. One of the ways in which livestock production can be increased is by reduction of losses due to disease. Estimates suggest that only a $6 \%$ reduction in disease could provide food for an additional 250 million people [1]. The situation is most serious in developing countries where $75 \%$ of the world's population resides. According to the Food and Agriculture Organization, it is estimated that up to $70 \%$ of the world's livestock resources exist in these regions, yet they account for only $30 \%$ of the world's meat output [1].

The effective control and treatment of parasitic diseases requires rapid, reliable and highly sensitive diagnostic tests, which can also serve to monitor the effectiveness of the therapeutic and prophylactic protocol. The usual immunological tests do not always meet these requirements and are not able reliably to distinguish between closely related species [2].

Protozoa are ubiquitous throughout aqueous environments and the soil, and play an important role in their ecology. Protozoa occupy a range of trophic levels. They also play a vital role in controlling bacteria population and biomass. Farm animals are usually infected with several species of parasites and they are also confined to pasture or pens. Parasite eggs, larvae, and cysts are intense in soil. One of the most important aspects of animal protozoology is transmission to humans. These are called zoonosis. Some of zoonotic diseases are common and important to public health [3].

Documented in recent studies, multiplex PCR assays are both more sensitive and specific than microscopy for the detection and identification of pathogenic protozoa [4]. However, despite a rapidly growing field of molecular and genetic technologies for the clinical microbiology laboratory, diagnostic developments for intestinal protozoan parasites have remained relatively stagnant. Some veterinarian and physicians interpret the presence of nonpathogenic protozoa as indicative of patient exposure to contaminated food or water, although there are no studies that have clearly demonstrated this to be fact. Adequate diagnosis of intestinal protozoa by the clinical laboratory is limited by many factors. There is increasing demand for lowcomplexity, high-throughput, and cost-effective complements to (or replacements for) the labor-intensive microscopy-based approaches to protozoan diagnosis. 


\section{Haemoparasitic protozoan}

Babesiosis: Babesiosis is an infectious tick- borne disease of livestock that characterized by fever, anemia, haemoglobinuria and weakness. The disease also is known by such names as bovine babesiosis, piroplasmosis, Texas fever, red water, tick fever, and tristeza [5]. The disease also is a haemoparasitic disease caused by protozoa of the genus Babesia (Phylum: Apicomplexa), which infects mainly ruminants [6]. Infection of a vertebrate host is initiated by inoculation of sporozoite form of parasites into the blood stream during the taking of a blood meal [7].

Bovine babesiosis disease is caused by at least six Babesia species. Bovine babesiosis associated with $\mathrm{B}$. bigemina and $\mathrm{B}$. bovis is the most important disease of tropical and subtropical regions between $40^{\circ} \mathrm{N}$ and $32^{\circ} \mathrm{S}$. Both species are transmitted transovarially by Boophilus ticks, but only tick larvae transmit B. bovis, whereas nymphs and adults transmit B. bigemina [7]. In Europe, babesiosis is caused by Babesia divergens, an intraerythrocytic parasite that can persist for $>13$ months in the organs of infected cattle. The distribution of $\mathrm{B}$. divergens reflects its triphasic telotropic tick vector, Ixodes ricinus, which is widespread across Western Europe and North Africa [8]. B. major occurs in Europe, North Africa and South America. B. major is transmitted by the three host tick Haemaphysalis punctata [9].

\section{Clinical examinations}

Incubation period is $2-3$ weeks. B. bigemina and B. bovis produce acute syndromes which are clinically indistinguishable, and are characterized by high fever $\left(41^{\circ} \mathrm{C}\right)$, anorexia, depression, weakness, cessation of rumination, and a fall in milk yield. Haemoglobinuria can be seen, the color of urine is dark-red to brown. Respiratory and heart rates are increased, and the red conjunctivate and mucous membranes change to the extreme pallor of severe anemia. Abortion occurs in pregnant animals [10]. Sub acute syndrome also occurs in young animals, but fever is mild and haemoglobinuria is absent [7].

In cerebral babesiosis, hyperexcitability, convulsions, opisthotonos, coma, and death, may be observed in cattle infected with either B. bigemina or B. bovis, but especially with the $\mathrm{B}$. bovis. Central nervous system signs are caused by brain anoxia resulting from severe anemia [5].

In sheep develop fever and parasitemia within 2 to 4 days; the clinical signs of the disease include anorexia, listlessness, anemia, moderate jaundice and haemoglobinuria. In intact animals, hyperthermia returned to normal on the fourth day after the peak pyrexia, and parasitemia is eliminated within the course of the disease [11].

\section{Diagnosis}

Blood smears and clinical finding are useful in acute cases of piroplasmosis, but are not sufficient in subclinical cases. The complement fixation test is used serological test for bovine babesiosis. The most commonly used tests are ELISA, PCR and a DNA probe, which can detect specific parasitemia at very low levels of infection [7]. Recently, the 'reverse line blot (RLB) is a versatile technique for simultaneous detection and identification of small ruminant piroplasm species, based on the recognition of specific gene regions by oligonucleotide probes [12-14].

\section{Treatment}

After the haemoglobinuria or cerebral signs, prognosis is not well. In acute cases that PVC values are above $12 \%$, treatment will be successful. Supportive therapy such as blood transfusions ( $4 \mathrm{~L}$ of whole blood per $250 \mathrm{~kg}$ of body weight), fluids, hematinics, and prophylactic antibiotics are important [5]. Babesiosis can be treated using

Diminazene aceturate $(3-5 \mathrm{mg} / \mathrm{kg})$

Phenemidine diisethionate $(8-13 \mathrm{mg} / \mathrm{kg})$

Imidocarb dipropionate (1-3 mg/kg)

Micarbalide diisethionate (5-10 mg / kg) [5,7,9,15,16].

The control of the disease depends on effective quarantine to prevent the introduction of the vector tick. The control of ticks by dipping or spraying animals at risk with recommended acaricides. In routine surgery, Care should be taken to prevent accidental transfer of blood from one animal to another (e.g., castration, dehorning). In addition, in cattle, the selection and breeding of cattle which acquire a high degree of resistance to ticks is practiced. Widespread use of tick vaccines may also have a significant influence on the incidence of infection in cattle $[5,7,9]$.

\section{Theileriosis}

Theileriosis is caused by Theileria spp. in cattle, goats, sheep and wild and captive ungulates [10]. Theileriosis is a haemoparasitic disease caused by protozoa of the genus Theileria (Apicomplexa). Theileria species affect domestic and wild ruminants, especially in Africa, Europe, Australia, and Asia [17]. The parasites are transmitted by tick. These parasites undergo repeated merogony in the lymphocytes ultimately releasing small merozoites, which invade the red cells to become piroplasms. Theileriosis, have a variety of tick vectors which cause infections ranged from clinically inapparent to rapidly fatal [9].

In bovine, Tropical Theileriosis (Mediterranean coast fever), occurs in Mediterranean countries, Middle East, Indian and China, and is caused by T. annulata [7]. The tick vectors are Hyalomma dentritum in North Africa and in the Mediterranean countries, $\mathrm{H}$. dentritum and $\mathrm{H}$. dromedaii in central Asia, and H. marginatum in India $[7,9]$. In endemic areas indigenous cattle are relatively resistant while modified cattle, especially European breeds, are highly susceptible [9]. Theileria orientalis complex is a milder disease than East coast fever and Tropical Theileriosis, and called benign theileriosis in cattle [7]. The tick vectors are Ambylomma variegatum, A. cohaerens, A. haebraeum, Haemaphysalis bispinosa that these vectors are the probable vectors in Australia [9]. Theileria 
velifera has been described in cattle and zebu and is very mild theileriosis in Africa [7,9]. The tick vectors are Ambylomma variegatum, A. lepidu and A. haebraeum [9]. Theileia taurotragi has been described in cattle, antelope and eland. Geographical distribution of this disease is in Africa. The tick vectors are Rhipicephalus appendiculatus and Rhipicephalus pulchellus [9]. Theileria mutans has been seen in cattle and deer [18]. Theileria hicri is malignant theileriosis of small ruminants [19], and is enzootic in North Africa, Middle East, China and India. The tick vectors are Rhipicephalus bursa and Hyalomma anatolicum [9].

Theileria ovis is benign theileriosis in Africa [7]. But in China Theileria ovis is a serious disease [20]. The incidence and mortality rates of Theileria ovis in adult sheep and goats were have found $17.12 \%$ and $65.78 \% ; 8.06 \%$ and $73.33 \%$ respectively in China [21]. In Turkey, prevalence of infection of T. ovis in sheep and goats were having been $64.19 \%$ and $12.36 \%$, respectively [22]. The tick vectors of disease are Rhipicephalus bursa in the Mediterranean and Rhipicephalus evertsi in Africa [9].

\section{Clinical examinations}

Theileia species are classified in to 2 groups. In first group (T. parva and T. annulata), proliferate is seen in lymphocytes but in the second group (T. orientalis) it is seen in erythrocytes that causes hemolytic anemia [23].

In Theileria parva incubation period is approximately1-3 weeks [7]. One or two days later, the first clinical sign is generalized swelling of the superficial lymph nodes, eyes, ears and submandibular regions. After few days there is anorexia, decreased milk production, loses condition, ceases rumination, rapid heartbeat, petechial haemorrhages under the tongue and on the vulva [9]. In cerebral theileriosis there are localized nervous signs and convulsions, tremor, salivation and head pressing [7].

In Theileria annulata, pyrexia, anorexia, enlargement of superficial lymph nodes, nasal and ocular discharges and salivation is the most common signs. Constipation is recorded in some cases. Respiratory distress, coughing and pulmonary oedema are seen [24].

In Theileria orientalis clinical signs are associated with anemia, jaundice and lymphadenopathy [9]. Clinical signs in Theileria velifera are not reported but in Theileria taurotragi mild fever and anemia are reported [9].

In Theileria hicri which is very pathogenic in sheep and goats, in the acute form there is fever, inappetence, ceases rumination, weakness, enlargement of superficial lymph nodes, diarrhea, jaundice, hemorrhage in submucous may occur. In chronic form there is fever, inappetence, emaciation, anemia and jaundice [9]. Theileria hicri is not reported in Turkey [22]. Theileria ovis that is benign theileriosis in sheep and goats clinically is mild [9].

\section{Diagnosis}

Investigation of giemsa-stained blood smears and lymph node biopsy will reveal piroplasms in erythrocytes and schizonts in lymphocytes. For diagnosis, indirect fluorescent antibody test (IFAT) and indirect enzyme-linked immunosorbent assay (ELISA) are the most commonly used techniques. The ELISA tests are more sensitive than IFAT [7,9].

\section{Treatment}

Buparvaquone is the most effective drug and the recommended dose in cattle, sheep and goat is $2.5 \mathrm{mg} / \mathrm{kg} \mathrm{BW}$ $[7,9]$. In control of the disease use of genetically resistant breed, a judicious and selective application of acaricides at 3week intervals and the use of vaccines are recommended [7].

\section{Trypanosomosis}

Member of the genus Trypanosoma are lived in the bloodstream and tissues of cattle, sheep, and goats in the entire world. These are flagellated protozoal agents that produce a variety of very serious disease of human and animals, but many of them are nonpathogenic [25]. Trypanosomosis is one of the most important diseases of animals and human. Most African species are transmitted by the tsetse flies [9]. There are 7 species of Trypanosoma species in cattle, sheep, and goat but all of them may not be pathogenic.

\section{Clinical examinations}

Clinical findings are based on the speed of onset of anemia and the grade of organ impairment. Trypanosomosis can be acute, subacute, or chronic. In acute form abortion, drop in milk, depression, anorexia can be seen. Hyperemic mucous membranes and lacrimation also can be occurring. In subacute form clinical signs include weight loss, enlargement of lymph nodes and dry hair coat. In chronic form dull, dry hair coat, inelastic skin, lethargy, pale mucous membranes and exercise intolerance may be seen [16]. T. theileri rarely causes clinical signs, but sometimes parasitemia may develop [16].

\section{Diagnosis}

Diagnosis can be based on the clinical findings, presence of vectors, appearance of trypanosomes on a fresh blood smear, or a Giemsa-stained blood smear. Indirect fluorescent antibody test (IFA) and the enzyme-linked immunospecific assay (ELISA) test are used for diagnosis [16].

The first nucleic acid-based detection and characterization of trypanosomes was done by using the genes coding for trypanosome variable surface glycoprotein (VSG's) [26-28]. These probes did not cross-hybridize to other trypanosome species and even distinguished groups within the species Trypanosoma congolense [29]. Nucleic acid probes have thus been developed that can distinguish between closely-related trypanosome species [30-32] and that can detect the parasite in the tsetse fly vector [33,34]. These probes are all based on repetitive DNA sequences and can detect as few as 100 trypanosomes by dot-blot hybridization [35].

\section{Treatment}

The most common drugs that are used for treatment of 
trypanosomosis are shown below:

Diminazene aceturate $3.5-7 \mathrm{mg} / \mathrm{kg}$ BW.

Homidium bromide and chloride $1 \mathrm{mg} / \mathrm{kg}$ BW -Pyrithidium bromide $2 \mathrm{mg}$ / kg BW.

Isometamidium $0.25-1 \mathrm{mg} / \mathrm{kg} \mathrm{BW}[7]$.

Vector control can help to control or prevent trypanosomosis. Insecticides can be used for prevent bites by tsetse flies and other flies [16].

\section{Intestinal protozoan parasites}

Coccidiosis: Coccidiosis is a protozoan parasitic (genus Eimeria) disease that cause diarrhea in calves, lambs and kids [7]. There are 12 species of Eimeria in cattle but all of them may not be pathogenic. the disease is dependent on the destroy of the crypt cells of the intestinal mucosa because in the ruminant small intestine is very long and providing a high number of host cells and is a potential for parasite replication with minimal damage. Some E. species that invade the large intestine cause pathological changes, especially when large numbers of oocysts are ingested in a short period of time [9].

In healthy nonimmune animals when number oocysts ingested is low, the animals show no clinical signs of disease but in many oocysts condition, rupture and exfoliation of intestinal cells triggers intestine function and causes loss of blood, fluid, albumin and electrolytes into the intestine. Disaster of mucosal capillaries of intestine can cause to hypoproteinemia and anemia. Secondary bacterial infection may cause severe enteritis [36].

Clinical examination: In most clinical cases the temperature is normal or subnormal, Disaster of epithelial cells of intestine cause sometimes bloody diarrhea. Dehydration may occur but anemia occasionally may be seen. In severe infections, diarrhea which may be mucoid or bloody, tenesmus, abdominal pain, anorexia, dehydration and weight loss are the common clinical signs in Coccidiosis [7,36].

In the calves that infected with high number of oocysts may developed dysentery. Clinical Coccidiosis occurs rarely in adult cattle [7].

Coccidiosis in lambs is widely similar to that in calves, but dysentery does not usually occur. In infected kids clinical signs are associated with watery diarrhea, dehydration, anorexia, and weight loss [36].

\section{Diagnosis}

Diagnosis is based on history, clinical and necropsy findings, and microscopic examination of feces. Acute Coccidiosis can be diagnosed by direct examination of feces but in chronic Coccidiosis that very low oocysts number are seen in feces, direct examination of feces may not be adequate [37].

\section{Treatment}

Coccidiostats drugs are used for treatment. All animals in the flock should be treated. Trimetoprim+Sulfadoxine (16-24 $\mathrm{mg} / \mathrm{kg}$ ) can be used for three days by intramuscularly in lambs and kids [38] Amprolium (10 mg/kg BW) for 5 days or $65 \mathrm{mg} /$ kg BW one dose can be effective in calves [7]. Diclazuril and toltrazuril are also coccidiocidal drugs $[39,40]$. Suggested that toltrazuril is more effective than sulphadimine and amprolium in E. Bbovis and E. zuernii oocysts shedding in buffalo calves. Because of the low serum vitamin $C$ levels in lambs with Coccidiosis, administration of vitamin $\mathrm{C}$ is suggested to be useful combined with the classical treatment [41].

Hygiene in the house, minimization of predisposing factors, avoiding the overcrowding of animals in the pens, control of the pastures for parasite are important factors for the control of Coccidiosis.

\section{Avian coccidiosis}

One of the most common \& expensive diseases of poultry production

Chickens

- 9 species of eimeria involved

- Eimeria acervulina - Most frequently encountered

- Eimeria tenella - Most pathogenic (high mortality)

- Site of infection ranges from small intestine to cecum depending on species involved

- Intestinal / cecal lesions range from minor to round, white/grey plaques to severe necrotic cores and hemorrhage with significant blood loss

\section{Clinical signs}

- Bloody droppings and hemorrhagic diarrhea beginning 4 days post infection

- Acute death (high mortality rates)

- Emaciation, pallor \& inappetence.

\section{Control and treatment}

- Isolate sick birds; treat healthy birds with anti-coccidian medications (treating sick birds is futile)

- Almost all poultry flocks receive preventative medication

- Ionospheres (monensin, salinomycin, lasalocid)

- Amprolium

- Decoquinate

- Resistance is becoming widespread

- Drugs must be rotated or use Ashuttle@ program (one drug in starter feed, another in grower feed)

- Vaccines have been developed but problems with administration 
- Raise young chickens separate from older birds (segregation of industry), All-in-All-out strategy

- Environment as in general section.

\section{Giardiasis}

Giardiasis is the infection caused by the flagellate intestinal protozoan, Giardia intestinalis, which is also known as G. duodenalis, or G. lamblia. Infection occurs in a wide range of domestic and wild animals and also humans. G. intestinalis is a potential pathogen in livestock, causing diarrhea, weight loss, poor condition and lethargy [42]. The parasite is a noninvasive and colonizes the mucosal surface of the small intestine.

\section{Clinical examinations}

Clinical signs of giardiasis include acute or chronic diarrhea, dehydration, weight loss, abdominal pain and reduction in weight gain. The diarrhea may be continuous or intermittent.

\section{Diagnosis}

Diagnostic methods for introduce of giardia include direct microscopy, fluorescent antibody staining, ELISA, and PCR [43].

Requires multiple fecal samples (3 consecutive or 3 over 5 days) as cyst shedding is intermittent.

\section{Fecal flotation}

Gold Standard: fecal flotation with centrifugation in ZnSO4 (with or without Lugol's iodine stain)

$>$ Cytoplasm within cysts collapses producing a crescent shaped refractile osmotic artifact.

\section{Direct smear}

$>$ Saline smear of fresh diarrhea, trophozoites movement (via flagella) - 'falling leaf'

$>$ Trophozoites die quickly so sample must be observed soon after collection (i.e. per rectum) or within $\sim 20-$ 30 minutes of 'deposit' \& kept at body temperature in humid environment to avoid desiccation.

$>$ Cysts may be observed in high numbers

Lugol's iodine can be used to stain both trophozoites \& cysts

\section{Antigen detection}

\section{$>$ Detect Giardia-specific antigen}

$>$ Pro Spec T Fecal ELISA (micro plate - multiple samples) - detect infections in cats \& dogs (100 \& 96\%, sensitivity $\&$ specificity respectively)

$>$ IDEXX SNAP Giardia test (lateral flow ELISA - individual samples)

$>$ Based on cyst wall protein released into the feces during encystations

\section{Approved for cats \& dogs (> 90\% sensitivity \& specificity)}

*** No current test is $100 \%$ reliable; therefore, best to use a combination of centrifugal fecal flotation \& antigen testing. Accuracy increases with more than one fecal sample analyzed per animal re: intermittent shedding of cysts.

\section{Treatment}

Infected sheep and goats can be treated with fenbendazole (5-10 mg / kg) for 3 days [37]. Fenbendazole (10 mg $/ \mathrm{kg} \mathrm{BW}$ daily for 3 days) and albendazole (20 $\mathrm{mg} / \mathrm{kg}$ BW daily for 3 days), have been shown also to be effective in calves $[7,44,45]$ demonstrated the efficacy and safety of a 5 day treatment with paromomycin against an experimental Giardia infection in calves. [46] Suggested that five day treatment with Trimethoprim + Sulfodoxine and multivitamin complexes can be effective in the prevention and treatment of Giardia intestinalis in lambs and kids. Re-infection frequently occurs if the sources of contamination are not eliminated and the frequency of transmission is high [44].

\section{Cryptosporidiosis}

Cryptosporidium are protozoan parasite with at least 13 species occurring in mammals, birds, and fish, but only 2 of these species are important in livestock animals $[7,9]$. Cryptosporidium species are intracellular protozoan parasites causing gastrointestinal disease and diarrhea, and they are important infection in young ruminants.

\section{Clinical examinations}

Infections that caused by Cryptosporidium andersoni are usually asymptomatic, although depressed weight gain in calves and milk yields in milking cows have been reported [9]. In Cryptosporidium parvum infections, clinical signs are characterized by anorexia, depression, weight loss, diarrhea, dehydration, high morbidity and possibly death because of dehydration. Cryptosporidium parvum can cause diarrhea in calves 5 to15 and in lambs and kids 5 to10 days of age [7,37]. Relapses of diarrhea are quite common, and Cryptosporidium parvum usually occurs as a component of mixed infections [37].

\section{Diagnosis}

Oocysts can be detected using Ziehl-Nielsen stained fecal smears Cryptosporidia can be diagnosed by fecal flotation. A number of molecular and immunological assays are available for diagnosis for example Immunofluorescence (IF) or EnzymeLinked Immunosorbent Assays (ELISA) [9]. Cryptosporidiosis is a zoonotic disease, and human can become infected from handling infected animals or feces.

\section{Treatment}

There is no effective drug for treatment of cryptosporidiosis in ruminants [37]. Halofuginone has efficacy in calves with diarrhea due to Cryptosporidium parvum. Halofuginone is reported to reduce oocyst shedding and the intensity of diarrhea. Oral dose of $0.1 \mathrm{mg} / \mathrm{kg}$ BW daily for 7 days can reduce oocyte excretion [46]. 
Decoquinate, $2.5 \mathrm{mg} / \mathrm{kg}$, can be effective in prevention of cryptosporidiosis in kids and goats [37]. Cryptosporidiosis in young animals should be treated with fluid therapy and correction of acid-base disturbance.

The control of disease is based on the minimize transmission between the source of the organism and young animals. During the course of the diarrhea, diarrheic young animals should be isolated from healthy animals [16]. The best control of cryptosporidiosis comes from calves, lambs, and kids getting adequate immunity through colostrum after birth.

\section{Specimen collection}

Optimal recovery and microscopic identification of protozoa from patients with intestinal infections is dependent on proper collection and preservation of fecal specimens. Well-recognized factors that influence the sensitivity of parasite examinations include patient medications, specimen collection interval, and the preservation of stool prior to testing [47]. The diagnostic yield of the O\&P is also significantly impacted by the number of stool specimens collected and submitted to the laboratory for testing. Many intestinal protozoa are irregularly shed, and data suggest that a single stool specimen submitted for microscopic examination will detect 58 to $72 \%$ of protozoa present $[48,49]$. However, alternative approaches have been proposed to help curtail unnecessary testing, including application of an algorithm that requires a negative specimen and persistence of symptoms before a second or third specimen is analyzed by the laboratory [48]. Specimens may also be pooled prior to screening based on microscopy. In contrast, the enhanced sensitivity of molecular detection methods may require only 1 specimen for testing to achieve sensitivity equal to, if not greater than, microscopy. One study demonstrated a $14 \%$ increase in yield for gastrointestinal protozoa when a realtime PCR was performed on a single stool specimen, compared to microscopy on three specimens [50].

\section{Specimen (Feces) preservation}

Preservation in $10 \%$ formalin is necessary when faeces cannot be examined within the prescribed time interval. These specimens can be stored for several months. However it should be noted that it has its drawbacks which include its interference with PCR especially after extended fixation time, its inadequate preservation of morphology of the protozoan trophozoites as well as its non-suitability for some smears stained with trichrome stain [51]. There are many microscopic artifacts that can be found in faeces which may be confused with trophozoites.

Visualization of motility in unpreserved specimens may facilitate diagnosis; this technique is impractical for most laboratories, as transport of fresh feces to the laboratory for testing is rarely within the requisite time frame for examination (i.e., 30 to $60 \mathrm{~min}$ ). A variety of fecal fixatives have been developed and modified in recent decades for use with traditional microscopic examination. Those that remain widely used and commercially available include formalin, sodium acetate-acetic acid-formalin (SAF), Schaudinn's fluid, polyvinyl alcohol-containing fixatives (mercury, copper, or zinc based), and mercury-free/formalin-free fixatives. A twovial collection system, consisting of one vial containing 5 to $10 \%$ buffered formalin for use in concentrated wet mounts and a second vial containing a polyvinyl alcohol-based preservative for permanent stained smears, is considered the "gold standard." However, concern over working with toxic formalin in the laboratory and the environmental impact and disposal costs associated with the use of mercury-based fixatives have led many to consider alternate preservatives and single-tube collection systems [52] SAF may be used to achieve this goal, if coupled with iron hematoxylin for the permanent stained smear; however, for laboratories desiring to maintain the trichrome stain, SAF is not a valid option, as poor-quality results have been documented with this combination.

\section{Specimen tranportation, storage and processing}

Use aseptic technique. Collect specimens in appropriate CE marked leak proof containers and transport in sealed plastic bags, with the exception of Sellotape slide/perianal swab for $E$. vermicularis ova which should be transported in a sealed plastic bag [53]. In the case of CSF, any inoculated plates should also be transported in a robust, CE marked leak proof container. Compliance with postal, transport and storage regulations is essential. Laboratory procedures that give rise to infectious aerosols must be conducted in a microbiological safety cabinet [54].

Disposable gloves should be worn for all Parasitology investigations.

\section{Parasite diagnostic techniques}

Epidemics among animals are still one of the main obstacles to the increase in production of animal protein and contact with vector-borne diseases often results in considerable losses [55]. The most reliable way to diagnose a parasitic infection is by detection and identification of the infecting organism Laboratory diagnosis is a basic step in the evaluation of the disease process, at times confirming a presumptive diagnosis or providing evidence of an unsuspected agent of disease. However, failure to demonstrate or recover a parasite does not exclude the possibility of infection. Many of these parasites, especially the protozoa, can be identified only by microscopic examination. This requires considerable skill and apart from being time consuming and labour-intensive the method has limitations. This also applies to most of the commonly used serological techniques.

\section{Direct identification}

Parasitic infections are usually diagnosed from samples of faeces, urine, blood and tissue.

Faeces: Evidence of intestinal parasitism, apart from the general clinical signs, is obtained from faecal or post-mortem examination. There is no "general" technique, nor is there an "ideal" technique for the microscopic examination of faeces. In fact, a reliable diagnosis can usually be made only by using a combination of several techniques [56], such as:

Citation: Hussen SM (2020) A Review on Intestinal and Blood parasitic (Haemoparasite) protozoans. Int J Vet Sci Res 6(2): 164-172. 
Direct saline smear: This procedure provides only an indication of the parasites present and cannot be used quantitatively. To prepare a direct faecal smear a drop of saline is placed in the centre of a microscope slide and a $2 \mathrm{mg}$ faecal sample is suspended in this drop without spreading it. This is then covered with a cover slip and examined [57].

Stained smears: This type of smear is essential for accurate diagnostic detail and is also suitable for long-term storage for record purposes. The two stains generally used are haematoxylin and trichrome $[56,57]$.

Parasite concentration in faeces by flotation: This is used for the identification of oocysts of coccidia [56] and helminth eggs. One drawback of this technique is that there is not always a direct relationship between the numbers of eggs in faeces and the number of parasites present.

Urine: Examination of urine sediment is used mainly for the identification of Encephalitozoon cuniculi and Schistosoma eggs [58]

Blood: Testing is used to identify the various stages of blood parasites and is routinely applied to diagnose malaria, theileriosis, babesiosis, anaplasmosis, ehrlichiosis, trypanosomiasis and most types of filariasis [56]. Trypanosoma can also be diagnosed with wet smears. Depending on the application and purpose, two types of blood films are used.

Thin blood films [57] are useful for studying morphological changes of blood cells and blood parasites. The main disadvantage is that sample volume is small, making the detection of low parasitemia and carrier animals difficult.

Thick blood films [58] contain 6 to 20 times as much blood per unit area as thin films. The thick film is suited for rapid diagnosis of parasitemia that is too low to be detected with thin films. This method is not suitable for detailed morphological studies of parasites.

Tissue: Recovery of protozoa or helminths from biopsy material is often an important aid to diagnosis. Lymph node, spleen, liver, lung, bone marrow or spinal fluid biopsies are frequently used to diagnose a variety of diseases [57].

Post-mortem: Post-mortem examination is currently the most effective way to accurately diagnose helminth infection [59]. Brain-cortex smears are examined for babesiosis (Babesia bovis), turning sickness (cerebral theileriosis) and cowdriosis.

\section{Indirect identification}

All methods for the direct identification of parasites fail if the parasite density in the specimen is below the sensitivity of the method employed, or if the parasite cannot be directly demonstrated due to the life cycle in the host (e.g. toxoplasmosis, echinococcosis and cysticercosis). In such cases indirect methods must be used. Ideally, serology should allow differentiation between recent and latent infections and should be able to demonstrate whether an animal is carriers as well as the elimination of the parasite after therapeutic measures have been applied. In practice, serology seldom achieves this. There is a lack of dependable tests for the sero-diagnosis of parasitic disease in animals. Commercially available tests present problems in reliability and interpretation of results. Costly, specialized apparatus is often needed to perform the tests [60]. With the majority of tests, specificity is not satisfactory and cross-reaction seldom allows distinction between closely related organisms. However, monoclonal antibodies may overcome this problem and enable the identification of highly specific antigen sites.

Tests commonly in use include the Complement Fixation Test (CFT), Immunodiffusion (ID), Indirect Haemagglutination (IHA), Indirect Immunofluorescent Antibody test (IFA), Enzyme-Linked Immunosorbent Assay (ELISA) and Radioimmunoassay (RIA) [61-63]. Less frequently used tests include latex agglutination, capillary agglutination and card agglutination [61-63]. Most of these tests are based on the reaction of antibodies with antigenic parasite components (whole or soluble) resulting in antigen-antibody complexes. These complexes are detected by the addition of antiglobulins coupled to fluorescein and rhodamine dyes, radioisotopes or enzymes. Because antibodies can persist for a long time after elimination of the parasites, another drawback of serology is that the demonstration of a specific antibody does not indicate the present parasitological status of the host. The results of a serological test are therefore retrospective. Sero-diagnosis of helminth infections is even more difficult because crossreactivity is more the rule than the exception. Only highly purified, defined antigens allow sero-diagnosis to the genus level; species-specific sero-diagnosis is unusual [61-63]. Antigen-capturing ELISA can be used for demonstrating infection with trypanosomes and Cowdria for instance.

\section{Antigen}

The application and reliability of serology is in many cases dependent on the availability of sufficient amounts of high quality antigen. The inability to culture many parasites in vitro and the lack of suitable animal models often hamper antigen preparation.

\section{Conclusion and recommendation}

Immunodiagnostic and molecular methods will become increasingly important for the detection and identification of blood parasites. However, light microscopy will still be required for the foreseeable future, and hematologists should maintain their proficiency in the morphological diagnosis of the common blood parasites.

Based on the above conclusion the following points are forwarded:

$>$ Proper diagnosis and treatment should be given for sick animal.

$>$ Awareness should be given for farmers about parasitic infections by government or other responsible bodies.

$>$ Young animal should be kept separately from older animal. 
$>$ Grazing on marshy area should be avoided or cutting or feeding strategy should be followed.

$>$ Regular eradication of flies (Tsetse) and ticks must be exercised.

$>$ Newly introduced animal to the flock should be dewormed.

\section{References}

1. Ristic M (1987) Progress in the immunoprophylaxis of haemoparasitic diseases of cattle. Agribusiness Worldwide 19: 9-10.

2. Voller A, De Savigny D (1981) Diagnostic serology of tropical parasitic diseases. J Immunol Methods 46: 1-29. Link: https://bit.ly/3qEgkrR

3. Sheather AL (1923) The detection of intestinal protozoa and mange parasites by a flotation technique. J Comp Path Ther 36: 266-275. Link: https://bit.ly/2JMqxSo

4. Seifert HSH (1973) Vorschläge zur Strategie der Bekämpfung von Vektorenseuchen bei Rindern a tropischen und subtropischen Standorten. Dt. tierärztl. Wschr, 15/16 348-352, 383-386.

5. Zaugg JL (2009) Babesiosis. In: Smith, B.P. (Eds): Large Animal Internal Medicine. Mosby, Elsevier, St. Louis 1157.

6. Melendez RD (2000) Babesiosis: An emerging zoonosis in temperate and tropical zones. A review. Revista Cientifica- Facultad De Ciencias Veterinarias 10: 13-18. Link: https://bit.ly/3n0gqb2

7. Radostits OM, Gay CC, Hinchcliff KW, Constable PD (2008) Diseases associated with protozoa. 10th Edn. In: Veterinary Medicine: A Textbook of Diseases of cattle, horses, sheep, pigs, and goats. Saunders Elsevier 14831540.

8. Jammes C (2009) Bovine anaplasmosis caused by Anaplasma marginale and bovine babesiosis. The situation in metropolitan France and on the island of Reunion. Bulletin de la Societe Veterinaire Pratique France 93: 34-41. Link: https://bit.ly/2VUNy87

9. Taylor MA, Coop RL, Wall RL (2007) Veterinary Parasitology. Third Edn. Blackwell Publishing.

10. Radostits OM, Gay CC, Blood DC, Hinchcliff KW (2000) Veterinary Medicine A Textbook of the Diseases of Cattle, Sheep, Pigs, Goats and Horses, 9th Ed. W.B. Saunders, Philadelphia.

11. Rahbari S, Nabian S, Khaki Z, Alidadi N, Ashrafihelan J (2008) Clinical, hematologic and pathologic aspects of experimental ovine babesiosis in Iran Iranian Journal of Veterinary Research 9: 59-64. Link: https://bit.ly/3oFE50V

12. Nagore D, Garcia-Sanmartin J, Garcia-Perez AL, Juste RA, Hurtado A (2004) Identification, genetic diversity and prevalence of Theileria and Babesia species in a sheep population from Northern Spain. Int J Parasitol 34: 10591067. Link: https://bit.ly/2VWx4MI

13. Lingli N, Jianxum L, Guiquan G, Miling M, Zhijie L, et al. (2009) Detection and differentiation of ovine Theileria and Babesia by reverse line blotting in China. Parasitol Res 104: 1417-1423. Link: https://bit.ly/33Z3ryW

14. Inci A, Ica A, Yildirim A, Duzlu O (2010) Identification of Babesia and Theileria species in small ruminants in Central Anatolia (Turkey) via reverse line blotting. Turkish Journal of Veterinary Science 34: 205-210. Link: https://bit.ly/2KahryQ

15. Cebra C, Cebra M (2002) Diseases of the Hematologic, Immunologic, and Lymphatic Systems (Multisystem Diseases). In: Pugh, D.G. (Eds): Sheep and Goat Medicine. Saunders, an Imprint of Elsevier. Philadelphia, Pennsylvania.

16. Cebra C, Cebra M (2002) Diseases of the Cardiovascular System. In: Pugh,
D.G. (Eds): Sheep and Goat Medicine. Saunders, an Imprint of Elsevier Philadelphia, Pennsylvania.

17. Allison RW, Meinkoth JH (2010) Anemia Caused by Rickettsia, Mycoplasma, and Protozoa. In: Weiss, D.J., and Wardrop, K.J. (Eds): Schalm's Veterinary Hematology.6th Ed. Wiley- Blackwell.

18. Carlson GP (2009) Theileriasis. In: Smith, B.P. (Eds): Large Animal Internal Medicine. Mosby, Elsevier, St. Louis 1160.

19. Miling M, Jianxum L, Guiquan G, Zhijie L, Youquan L, et al. (2009) A serological survey of ovine Theileriosis by ELISA. Chinese Journal of Veterinary Science 29: 1575- 1577.

20. Shuzhen G, Zhengphu Y, Guoxue W, Wenbiao W, Denglu M, et al. (2002) Epidemiology of ovine theileriosis in Ganan region, Gansu Province, China. Parasitol Res 88: 536-537. Link: https://bit.ly/3oyq596

21. Sayın F, Nalbantoglu S, Yukari BA, Cakmak A, Karaer Z (2009) Epidemiologica studies on sheep and goat Theileria infection. Ankara Universitesi Veteriner Fakultesi Dergisi 56: 127-129. Link: https://bit.ly/3qJbQ3k

22. Magona JW, Walubengo J, Olaho-Mukani W, Jonsson NN, Welburn SC, et al. (2010) Clinical features associated with seroconversion to Anaplasma marginale, Babesia bigemina and Theileria parva infections in African cattle under natural tick challenge. Vet Parasitol 171: 207-215.

23. Osman SA, Al-Gaabary $\mathrm{H}$ (2007) Clinical, hematological and therapeutic study on tropical theileriosis in water buffaloes (Bubalus bubalis) in Egypt. Vet Parasitol 146: 337-340. Link: https://bit.ly/39QxFYB

24. Ballweber LR (2009) Coccidiosis in food animals. In: Smith, B.P. (Eds): Large Animal Internal Medicine. Mosby, Elsevier, St. Louis, 1645-1647.

25. Lawrence JA (2004) Theileriosis of sheep and goats. In: Coetzer, J.A.W. and Tustin, R.C. (Eds): Infectious diseases of livestock, Volume One 2th Edn Oxford: Oxford University Press 498-499.

26. Majiwa PA, Matthyssens G, Williams R, Hamers R (1985) Cloning and analysis of Trypanosoma (Nannomonas) congolense IL Nat 2.1 VSG gene. Molec Biochem Parasitol 16: 97-108. Link: https://bit.ly/37MNNHV

27. Majiwa PA, Webster $P$ (1987) A repetitive deoxyribonucleic acid sequence distinguishes Trypanosoma simiae from Trypanosoma congolense. Parasitology 95: 543-558. Link: https://bit.ly/3IZqY8T

28. Williams RO, Young JR, Majiwa PA (1982) Genomic environment of Trypanosoma brucei VSG genes: presence of a mini chromosome. Nature (London) 299: 417-421. Link: https://bit.ly/3qF82Qu

29. Majiwa PA, Masake RA, Nantulya VM, Hamers R, Matthyssens G (1985) Trypanosoma (Nannomonas) congolense: identification of two karyotypic groups. EMBO J 4: 3307-3313. Link: https://bit.ly/3gv510c

30. Dickin SK, Gibson WC (1989) Hybridization with a repetitive DNA probe reveals the presence of small chromosomes in Trypanosoma vivax. Mol Biochem Parasitol 33: 135-142. Link: https://bit.ly/36YSsYb

31. ILRAD (1988) New tools for trypanosomiasis field studies. ILRAD Reports 6

32. Massamba NN, Williams RO (1984) Distinction of African trypanosome species using nucleic acid hybridization. Parasitology 88: 55-65. Link: https://bit.ly/3n5TE1C

33. Gibson W, Dukes P, Gashumba J (1988) Species-specific DNA probes for the identification of African trypanosomiasis in tsetse flies. Parasitology 97: 63 73. Link: https://bit.ly/33YmV6F

34. Kukla B, Majiwa PA, Young J, Moloo S, Ole Moi Yoi O (1987) Use of speciesspecific probes for detection and identification of trypanosome infection in tsetse flies. Parasitology 95: 1-16. Link: https://bit.ly/33XtrdP

35. Barker DC (1989) Molecular approaches to DNA diagnosis. Parasitology 99 S125-S146. Link: https://bit.ly/33Z3SJA

Citation: Hussen SM (2020) A Review on Intestinal and Blood parasitic (Haemoparasite) protozoans. Int J Vet Sci Res 6(2): $164-172$.

DOI: https://dx.doi.org/10.17352/ijvsr.000069 
36. Navarre CB, Pugh DG (2002) Diseases of the Gastrointestinal System. In: Pugh, D.G. (Eds): Sheep and Goat Medicine. Saunders, an Imprint of Elsevier. Philadelphia, Pennsylvania.

37. Ozmen O, Sahinduran S, Yukari BA (2004) Comparative evaluation on clinicopathological findings and treatment in acute and chronic Coccidiosis of lambs and kids. Indian Veterinary Journal 81: 1206-1209. Link: https://bit. ly/3gsJoOB

38. Matthewa J (2009) Abortion. 3th Edn. In: Diseases of the goat. Blackwell Publishing Ltd. Pp: 23- 41.

39. Ghanem MM, Radwaan ME, Moustafa AMM, Ebeid MH (2008) Comparative therapeutic effect of toltrazuril, sulphadimine and amprolium on Eimeria bovis and Eimeria zuernii given at different times following infection in buffalo calves (Bubalus bubalis). Prev Vet Med 84: 161-170. Link: https://bit.ly/3a1Uats

40. Sahinduran S, Sezer K, Buyukoglu T, Yukari BA, Albay MK (2006) Plasma ascorbic acid levels in lambs with Coccidiosis. Turkish Journal of Veterinary \& Animal Sciences 30: 219-221. Link: Link: Link: https://bit.ly/36YSeAb

41. Hunter PR, Thompson RCA (2005) The zoonotic transmission of Giardia and Cryptosporidium. Int J Parasitol 35: 1181-1190. Link: https://bit.ly/3a1U2ds

42. Gunn AA, Naylor JA, House JK (2009) Diarrhea. In: Smith, B.P. (Eds): Large Animal Internal Medicine. Mosby, Elsevier, St. Louis, 340- 363

43. Thompson RCA (2004) The zoonotic significance and molecular epidemiology of Giardia and giardiasis. Vet Parasitol 126: 15-35. Link: https://bit.ly/3gEOqHL

44. Geurden T, Claerebout E, Dursin L, Deflandre A, Bernay F, et al. (2006) The efficacy of an oral treatment with paromomycin against an experimental infection with Giardia in calves. Vet Parasitol 135: 241-247. Link: https://bit. ly/2JQsfCj

45. Ozmen O, Yukari BA, Haligur M, Sahinduran S (2006) Observations and immunohistochemical detection of Corona virus, Cryptosporidium parvum and Giardia intestinalis in neonatal diarrhea in lambs and kids. Schweiz Arch Tierheilkd 148: 357- 364. Link: https://bit.ly/33Z2xCy

46. Garcia LS (2009) Practical guide to diagnostic Parasitology. ASM Press, Washington, DC.

47. Branda JA, Lin TY, Rosenberg ES, Halpern EF, Ferraro MJ (2006) A rational approach to the stool ova and parasite examination. Clin Infect Dis 42: 972978. Link: https://bit.ly/373pMNP

48. Bruijnesteijn van Coppenraet LE, Wallinga JA, Ruijs GJ, Bruins MJ, Verweij JJ (2009) Parasitological diagnosis combining an internally controlled real-time PCR assay for the detection of four protozoa in stool samples with a testing algorithm for microscopy. Clin Microbiol Infect 15: 869-874. Link: https://bit. ly/373pMNP

49. Pietrzak-Johnston SM, Bishop H, Wahlquist S, Moura H, Da Silva ND, et al. (2000) Evaluation of commercially available preservatives for laboratory detection of helminthes and protozoa in human fecal specimens. J Clin Microbiol 38: 1959-1964. Link: https://bit.ly/370MisG

50. Nazer H, Greer W, Donnelly K, Mohamed AE, Yaish H, et al. (1993) The need for three stool specimens in routine laboratory examinations for intestinal parasites. Br J Clin Pract 47: 76-78. Link: https://bit.ly/2LgG6C9

51. Centers for Disease Control and Prevention Laboratory Identification of Parasitic Diseases of Public Health Concern - specimen collection Centers for Disease Control and Prevention. 2013. B, VI

52. Stark D, Al-Qassab SE, Barratt JL, Stanley K, Roberts T, et al. (2011) Evaluation of multiplex tandem real-time PCR for detection of Cryptosporidium spp.,
Dientamoeba fragilis, Entamoeba histolytica, and Giardia intestinalis in clinical stool samples. J Clin Microbiol 49: 257-262. Link: https://bit.ly/36VrSit

53. World Health Organization (1991) Basic laboratory methods in medical Parasitology, pages 77-78. Geneva: World Health Organization.

54. Advisory Committee on Dangerous Pathogens. Biological agents: Managing the risks in laboratories and healthcare premises. Health and Safety Executive 2005

55. Benbrook EA, Sloss MW (1961) Fecal examination in the diagnosis of parasitism. In Veterinary clinical Parasitology. lowa State University Press Ames, lowa 1-107.

56. Beaver PC, Jung RC, Cupp EW (1984) Technical appendix. In Clinical Parasitology, 9th Ed. Lea \& Febiger, Philadelphia 733-764.

57. Levine ND (1985) Laboratory diagnosis of protozoan infections. In Veterinary Parasitology. lowa State University Press, Ames, lowa 365-386.

58. Peters PA, Mahmoud AA, Warren KS, Ouma JH, Soingok TK (1976) Field studies of a rapid accurate means of quantifying Schistosoma haematobium eggs in urine samples. Bull WHO 54: 159-162. Link: https://bit.ly/2LgFYm9

59. Fripp PJ (1983) In An introduction to human Parasitology with reference to Southern Africa. MacMillan South Africa, Johannesburg. Link: https://bit. ly/33Swy6H

60. Arundel JH (1967) Field procedures for counting gastrointestinal worms in sheep and cattle. Aust Vet J 43: 592-597. Link: Link: Link: https://bit. ly/3gsu3x0

61. Fox JC, Jordan HE, Kocan KM, George TJ, Mullins ST, et al. (1986) An overview of serological tests currently available for laboratory diagnosis of parasitic infections. Vet Parasit 20: 13-29. Link: https://bit.ly/36ZfP3W

62. Weiland G (1988) Serology and immunodiagnostic methods. In Parasitology in focus (H. Mehlhorn, Ed.). Springer-Verlag, New York

63. Klein P (2008) Preventive and therapeutic efficacy of Halofuginone-lactate against Cryptosporidium parvum in spontaneously infected calves: centralized randomized, double-blind, placebo-controlled study. Vet J 177: 429-431. Link: https://bit.ly/3m3wWFQ

\section{Discover a bigger Impact and Visibility of your article publication with}

\section{Peertechz Publications}

\section{Highlights}

* Signatory publisher of ORCID

* Signatory Publisher of DORA (San Francisco Declaration on Research Assessment)

* Articles archived in worlds' renowned service providers such as Portico, CNKI, AGRIS, TDNet, Base (Bielefeld University Library), CrossRef, Scilit, J-Gate etc.

* Journals indexed in ICMJE, SHERPA/ROMEO, Google Scholar etc.

- OAI-PMH (Open Archives Initiative Protocol for Metadata Harvesting)

* Dedicated Editorial Board for every journal

* Accurate and rapid peer-review process

* Increased citations of published articles through promotions

* Reduced timeline for article publication

Submit your articles and experience a new surge in publication services (https://www.peertechz.com/submission).

Peertechz journals wishes everlasting success in your every endeavours.

Copyright: () 2020 Hussen SM. This is an open-access article distributed under the terms of the Creative Commons Attribution License, which permits unrestricted use, distribution, and reproduction in any medium, provided the original author and source are credited.

Citation: Hussen SM (2020) A Review on Intestinal and Blood parasitic (Haemoparasite) protozoans. Int J Vet Sci Res 6(2): 164-172.

DOI: https://dx.doi.org/10.17352/ijvsr.000069 